\title{
A autonomia como valor e articulação de possibilidades: 0 movimento dos professores indígenas do Amazonas, de Roraima e do Acre e a cons- trução de uma política de educação escolar indígena*
}

\author{
Rosa Helena Dias da Silva**
}

\begin{abstract}
RESUMO: O presente artigo procura verificar o papel cultural-políticopedagógico do movimento dos professores indígenas do Amazonas, de Roraima e do Acre na construção de uma política indígena de educação escolar. Trabalha-se com a concepção de "escola indígena" como nova forma de instituição educacional, definindo-a a serviço de cada povo, como instrumento de afirmação e reelaboração cultural. Uma escola que contribua na conquista de espaço político - no campo da educação - pelos povos indígenas, dentro do Estado brasileiro, buscando novas relações interculturais, no marco do reconhecimento do Brasil como país pluricultural, assim como a superação da perspectiva integracionista, contrapondo-se, assim, à idéia e à realidade das "escolas para os índios". São analisados ainda os limites e as possibilidades das escolas indígenas, como recurso político-cultural de afirmação das identidades no confronto com a realidade atual, ou em seu enfrentamento, no que se refere ao contato interétnico.
\end{abstract}

Palavras-chave: Autonomia, movimento indígena, educação escolar

\footnotetext{
* Este artigo é uma síntese das principais idéias da tese apresentada pela autora à Faculdade de Educação da Universidade de São Paulo, como parte dos requisitos para obtenção do título de doutor em Educação, em março de 1998. O título original da tese é: "A autonomia como valor e a articulação de possibilidades: Um estudo do movimento dos professores indígenas do Amazonas, Roraima e Acre, a partir dos seus encontros anuais" e teve orientação da professora doutora Roseli Fischmann. A tese foi elaborada com auxílio da Fapesp e do CNPq.

** Doutora em Educação pela USP; professora na Faculdade de Educação e Programa de Pósgraduação em Educação da Universidade do Amazonas; membro do Conselho Indigenista Missionário (Cimi) e assessora da Comissão dos Professores Indígenas do Amazonas, Roraima e Acre (Copiar). E-mail: rosahelena@internext.com.br
} 
O pessoal está se reunindo para mudar essa escola. Estamos nos reunindo para ver como seria a escola ideal para nós.

(Relatório do II Encontro dos Professores Indígenas do AM e de RR, Manaus, 1989)

(...) é necessário formar e valorizar profissionais voltados para a própria comunidade, visando à nossa autonomia $\mathrm{e}$ para que as escolas sirvam como instrumento para a permanência dos jovens em nossas aldeias e não como portas de saída. (Documento do IX Encontro dos Professores Indígenas do AM, de RR e do AC, S. Gabriel da Cachoeira,1996)

Introdução: Justificando uma escolha

O tema-título do presente artigo surge da importância do papel que os professores indígenas vêm desempenhando no atual momento histórico dos povos indígenas no Brasil, em sua prática concreta de construção de uma política indígena de educação escolar. ${ }^{1}$

Conforme analisou Silva (1995, pp. 9-10),

embora tão antiga quanto a colonização do Brasil, a escola indígena e, de modo mais amplo, a educação escolar presente em áreas indígenas passaram a ser objeto de reflexão e crítica e, em alguns casos, de uma "revolução pedagógica", há cerca de parcos vinte anos. (...) Nas aldeias e nas áreas indígenas, é também a década de 70 que vê as tentativas pioneiras de construção de uma educação escolar sintonizada com os interesses, os direitos e as especificidades de povos e culturas indígenas. (...) Esta tendência, ainda ausente ou incipiente em muitas localidades, é, no entanto, a grande novidade e o fruto principal de um processo recentemente iniciado, mas rapidamente amadurecido, do qual, os encontros e as associações de professores índios são hoje o pólo mais avançado.

Alguns pressupostos: Demarcando uma posição

Um dos pressupostos básicos deste trabalho é o entendimento e a afirmação de que têm existido historicamente formas próprias de edu- 
cação indígena, e de que as pedagogias indígenas constituem valores fundamentais, que devem também orientar os trabalhos escolares e a elaboração de uma política indígena de educação escolar. ${ }^{2}$

Um segundo pressuposto entende a escola não como único lugar de aprendizado. É extremamente importante reconhecer que os povos indígenas mantêm vivas as suas formas de educação tradicional, que podem contribuir na formação de uma política e uma prática educacional adequadas, capazes de atender aos anseios, interesses e necessidades diárias da realidade atual.

Como afirma Stephen Corry (1994), "os povos indígenas são sociedades viáveis e contemporâneas, com complexos modos de vida, assim como com formas progressistas de pensamento que são muito pertinentes para o mundo atual" (tradução da autora).

Um terceiro pressuposto inicial está ligado à avaliação de que a escola é hoje uma espécie de necessidade "pós-contato", que tem sido assumida pelos índios, mesmo com todos os riscos e resultados contraditórios já registrados ao longo da história.

De fato, é do âmbito deste texto defender que a escola, um dos principais instrumentos usados durante a história do contato para descaracterizar e destruir as culturas indígenas, pode vir a ser hoje na mão dos próprios povos indígenas - um instrumento decisivo na reconstrução e na afirmação das identidades. O desafio que se coloca é o de pensar as escolas indígenas em seus limites e suas possibilidades, dentro da realidade atual, cada dia mais norteada por tendências homogeneizadoras e globalizantes.

Vejamos algumas citações de professores indígenas que podem ilustrar essa perspectiva, quanto à presença da escola em suas vidas e quanto às possibilidades vislumbradas para o futuro:

Se não tivesse branco no meio dos tikunas, talvez até hoje não teria escola. (Prof. Alírio Mendes, tikuna - Relatório do I Encontro/ Manaus, 1988)

A escola entrou como um corpo estranho. A escola entra e se apossa da comunidade. Não é a comunidade que é seu dono. Hoje, os índios começam a dar as regras para o jogo da escola: "tá, você fica aqui, mas dessa forma!" Temos leis que dão respaldo, mas ainda não estamos sabendo usar. (Prof. Bruno, kaingang) ${ }^{3}$ 
Precisamos pegar esses mecanismos colocados de fora (no caso, a escola) e fazer deles parte da nossa sociedade. Precisamos nos organizar como povo: preservar nossa cultura, nossa língua... mas não podemos preservar a fome! (Prof. Orlando Justino, macuxi) ${ }^{4}$

Assim, poderia afirmar que, ao aceitar a escola, e mesmo reivindicála, os índios a têm "ressignificado", conferindo-lhe um novo valor: a possibilidade de decifrar o mundo "de fora", "dos brancos". Em síntese, decifrar a nova realidade advinda do contato. Longe de ser uma "adesão" a nosso modelo, é, nesse sentido, uma estratégia de resistência.

\section{Escolas indígenas, sociedade civil e Estado: Conquistando novas relações}

Para compreender melhor essa complexa problemática, é preciso inseri-la na história das relações políticas que se estabeleceram entre o Estado nacional e os povos originários do continente, contexto em que se situa a presente discussão sobre o papel, o dever e as responsabilidades do Estado quanto aos povos indígenas, interessando, neste caso, em particular, o direito à educação escolar. ${ }^{5}$

Como se sabe, a "problemática indígena" inicia-se com a chegada dos portugueses. Ao olharmos o processo de consolidação do Estado brasileiro durante os períodos colonial, imperial e republicano, podese afirmar que a presença dos povos genericamente denominados de indígenas sempre constituiu preocupação para as forças colonizadoras. É, então, nesse contexto histórico que se coloca a trajetória da educação escolar indígena.

Atualmente, a Constituição de 1988 inaugurou no Brasil a possibilidade de novas relações entre o Estado, a sociedade civil e os povos indígenas, ao superar - no texto da lei - a perspectiva integracionista, reconhecendo a pluralidade cultural. Em outros termos, o direito à diferença fica assegurado e garantido, e as especificidades étnico-culturais valorizadas, cabendo à União protegê-las.

É preciso lembrar que dentre os "bens indígenas" estão os de natureza material (riquezas naturais, patrimônio e integridade física dos membros das nações) e imaterial (valores culturais e morais), estando con- 
tidos neles todos os aspectos reconhecidos expressamente no art. $231 \mathrm{da}$ Constituição. É no contexto dessas garantias conquistadas que se enquadra o direito à educação escolar indígena específica e diferenciada.

O pressuposto básico deste trabalho - o direito à diferença - é tema que merece constantes reflexões, seja por sua própria complexidade, seja pelo elenco de tantas outras discussões que a ele se somam. Uma primeira reflexão diz respeito à forma como nossa sociedade olha para os índios, incluindo a questão do lugar que reserva para eles.

Oliveira, ao identificar nas relações entre Estado e povos indígenas um "colonialismo interno", diz que, a seu ver, este deveria ser substituído por uma "diplomacia interna" (1988, p. 10).

Para Price (1975),

\begin{abstract}
quem estranhar a palavra "diplomática" terá que admitir o seu próprio preconceito: que o índio é tão inferior que relações com ele não merecem o rótulo de "diplomáticas". Costumamos manter relações diplomáticas com Estados. Precisamos nos dar conta de que o Estado é só uma entre as várias formas de organização social, e fica claro que sociedades em contato devem manter relações diplomáticas, quaisquer que sejam suas formas de organização. $\mathrm{O}$ bom diplomata tem que saber alguma coisa sobre o país onde trabalha. Deve entender a política interna, os interesses econômicos, a etiqueta. Infelizmente, no indigenismo, a tendência é de se elaborar uma "política externa" sem saber nada das sociedades com que se trata. Nem se diferencia entre as várias sociedades; a mesma política indigenista aplica-se aos kadiwéu, aos marubo e aos fulniô. É como se se aplicasse a mesma política externa à China, à Guatemala e à África do Sul. (...) Nós indigenistas teremos que ser embaixadores em culturas estrangeiras, e não representantes de um exército vitorioso.
\end{abstract}

Podemos constatar que, apesar de todo contexto de violência e invasão cultural ao qual foram expostos os povos indígenas, um processo de resistência e oposição sempre foi desenvolvido por eles. Ao longo dessa história, escolas e programas oficiais de "educação para o índio" desempenharam papéis que tenderam a somar forças ao projeto integracionista, reforçando a tradição assimilacionista dominante na relação do Estado nacional com os povos indígenas. Basta lembrarmos o que propõe o artigo $50^{7}$ do Estatuto do Índio de $1973 .{ }^{8}$ 
Movimento indígena como formulador de políticas, ações e concepções: 0 exemplo dos professores

O que define e delimita a experiência analisada neste artigo é a questão da criação e da autogestão dos processos de educação escolar indígena. Esta é sua especificidade: que os próprios povos indígenas discutam, proponham e procurem - não sem dificuldades - realizar seus modelos e ideais de escola, segundo seus interesses e suas necessidades imediatas e futuras. É um dado novo que distingue, em sua raiz, essa experiência de outras em curso. Seria, de fato, tentativa concreta de transformar a "educação escolar para índio" em "educação escolar do índio". Nesse sentido, é um tema novo na história da educação escolar indígena no Brasil. ${ }^{9}$

O movimento dos professores indígenas do Amazonas, de Roraima e do Acre ${ }^{10}$ articula-se principalmente em seus encontros anuais e surgiu como resposta à necessidade de refletir sobre problemas comuns vividos pelos professores indígenas dessas regiões e de encontrar alternativas para uma mudança nos rumos da educação escolar.

Nesse processo de organização, os encontros anuais representaram momentos decisivos, nos quais as articulações culturais e políticas tornaramse possíveis, e as trocas de experiências e conhecimentos fizeram surgir uma nova concepção de educação escolar indígena, que respeita os conhecimentos, as tradições e os costumes de cada povo, valorizando e fortalecendo a identidade étnica, ao mesmo tempo em que procura passar conhecimentos necessários para uma melhor relação com a sociedade não-índia.

O conceito de professor indígena está ligado, como parte integrante, a uma definição mais ampla: a proposta de uma escola indígena. Significa que seu trabalho só pode se realizar eficazmente, segundo os ideais afirmados, num modelo realmente indígena de escola e que este só pode ser construído com a participação efetiva de todos: professores, lideranças, alunos e comunidade indígena.

Mosonyi (1996), em "Familia indígena y educación intercultural bilingüe", fala com clareza sobre esse aspecto fundamental da discussão:

nem a Educação Intercultural Bilíngüe, nem outros mecanismos de vitalização das características profundas da identidade poderão prosperar por tempo indefinido, senão pela via de um ataque à problemática de conjunto que, em dada conjuntura, atravessa uma 
comunidade ou etnia. É imperativo emoldurar qualquer esforço em um projeto comunal ou regional de alcance integral, que leve em conta parâmetros como as terras ancestrais e recém-adquiridas, uma economia que conjugue a auto-subsistência com o mercado de alguns produtos, uma organização participativa nos níveis de decisão, principalmente na resolução dos problemas de saúde, serviços e direitos humanos elementares. Se, de alguma maneira, não se contemplam todas essas vertentes, qualquer programação isolada está destinada ao fracasso.

Santos (1975), em seu livro Educação e sociedades tribais, publicação pioneira na temática especificamente vinculada à educação escolar indígena no Brasil, a fim de avaliar a possibilidade de educação formal (escolarização) com ensino bilíngüe, implementada em alguns postos da Funai no sul do país, aponta que um dos equívocos desse processo foi justamente a concepção de que a educação escolar, por si só, introduziria mudanças substanciais na vida indígena. Conclui, então, que os programas de escolarização deveriam fazer parte de um projeto mais amplo, valorizando os índios e sua cultura. $\mathrm{Na}$ análise desse autor, a problemática indígena tem causa num quadro sociopolítico, cultural e ideológico, e é nesse âmbito de complexidade que deverá ser equacionada. Creio que tal concepção abre caminho para a reflexão atual, que considera as escolas indígenas como parte de um projeto mais amplo de futuro dos povos aos quais elas servem.

Os encontros anuais têm possibilitado aos professores indígenas a aquisição de instrumental de discussão que lhes permite um nível de diálogo e relacionamento mais equilibrado perante os demais setores da sociedade civil e do Estado.

Como lembra Mosonyi (1996),

ainda segue predominando uma concepção institucional e formalizada da Educação Intercultural Bilíngüe: fundar escolas, formar ou reciclar professores, fazer programas, publicar textos pedagógicos, desenhar metodologias, e inclusive ganhar batalhas perante as autoridades nacionais, para essa iniciativa. Tudo isso é de suma importância, e estamos longe de haver cumprido sequer todos esses passos, nem mesmo nos lugares mais favoráveis. Porém, há outra série de problemas que precisam ser enfrentados, senão, é impossível avançar (...). Trata-se da relação entre esse tipo de educação 
e a vida familiar cotidiana, dentro da comunidade, já que a infância escolarizada pertence, em primeiro lugar, a suas famílias de origem.

\section{Considerações finais:}

Dúvidas e inquietações perante um debate em aberto

Procurei, ao longo do texto, contrapor-me a pelo menos duas visões de escola indígena que avalio insuficientes para explicitar a realidade atual e os anseios colocados pelo movimento dos professores indígenas do Amazonas, de Roraima e do Acre, com o qual tenho convivido - e aprendido - mais de perto. Uma primeira seria aquela que concebe a instituição escolar como parte da cultura da sociedade envolvente; assim sendo, sempre vai ser "paralela" ou "de fora", em resumo, "escolas para índios". A segunda concepção parte do princípio de que os índios, como todos os cidadãos brasileiros, "têm direito a uma boa escola", nos moldes que projetamos para nossa sociedade. Aí, como é fácil observar, permanece a perspectiva das "escolas para índios".

Objetivei ainda mostrar o dinamismo dialético da questão: a escola "pode vir a ser" algo que contribua na vida dos povos indígenas. Nessa perspectiva, escolas indígenas seriam, de fato, projetos indígenas de escolas, deixando de ser propostas de fora, "ofertas" de quem quer que seja: governo, ONGs, igrejas, universidades, e passariam a ser parte de um processo mais amplo que, necessariamente, deve estar nas mãos dos principais interessados: os povos indígenas.

Sinto que aqui reside a grande dificuldade (não só para os índios, mas muito mais para nós): pensar as escolas indígenas é pensar novas relações entre os povos indígenas, o Estado e a sociedade civil. É pensar nosso futuro comum, realmente assumindo a pluralidade constituinte de nosso país. É permitir-se o difícil exercício da diversidade, reconhecendo as diferenças e olhando-as não como problema, mas, ao contrário, como valor. Realmente projetar um amanhã em que as diferenças e singularidades - as diferentes lógicas e racionalidades, as diversas maneiras de ver o mundo - possam compor um cenário complexo e rico (ético e esteticamente belo), contribuindo para a superação do ideal de homogeneidade, ou seja, de uma certa uniformização de idéias, valores e projetos que historicamente predominaram. Utopia? Prefiro chamar de esperança, conforme Paulo Freire (1997), em seu livro Pedagogia da autonomia, ao vislumbrar a história como "tempo de possibilidades". ${ }^{12}$ 
Nesse contexto, qual será o papel das escolas indígenas na realidade do contato interétnico: confronto? Conflito? Diálogo? Tendo como premissa a possibilidade da existência de escolas que, em processo de construção permanente, possam ser chamadas com propriedade de escolas indígenas, procurei explicitar as características e os pressupostos que qualificam uma política indígena de educação escolar. Em outras palavras, o que garante a possibilidade da concretização de propostas indígenas de escola.

Um primeiro pressuposto fundamental é que as escolas sejam entendidas como parte integrante de um projeto mais amplo vivido pelos povos indígenas na busca de garantir seu presente e seu futuro, como sociedades e culturas autônomas. Nas palavras de Márcio Silva (1994),

sabemos, como educadores, que onde quer que haja escola, ela sempre é parte de um projeto que a transcende. Pensar a escola indígena sem a consideração da relação entre essa instituição e a divisão do trabalho tal como se define na sociedade em que está inserida (o seu projeto social) é algo que me parece de uma ingenuidade comprometedora. O que importa primeiramente ao movimento de professores indígenas do Amazonas, Roraima e Acre hoje é precisamente a luta pelo direito dos povos indígenas a ter em suas mãos o poder sobre os programas de educação escolar que se desenvolvem em suas áreas, uma vez que constituem instrumentos imprescindíveis na construção de seus destinos.

O professor Euclides Pereira, macuxi, de Roraima, não deixa dúvidas ao afirmar que:

(...) estamos hoje, de certa forma, obrigados a assumir para nós aquilo que não é nosso, que não faz parte da nossa cultura. São costumes desta sociedade que invade as nossas malocas, e a gente, sem perceber, vai absorvendo essa situação e prejudica nossa cultura. Essa situação, de certa forma triste, em que se busca, através da educação, uma possível saída para os problemas. (...) Às vezes eu vejo que a escola pode ser o caminho pra chegar a mudar essa mentalidade. A partir do momento em que se trabalha com as crianças. Porque se separarmos a educação, se a dissociarmos da vida do índio... Eu acredito que a nossa forma de viver, a nossa forma de ver o mundo tem que ser preservada, porque a vida dessa sociedade não é mais admitida por ela mesma. Porque - você já pensou? -, crianças abandonadas; mulhe- 
res prostituídas... Eu acredito que nós não somos obrigados a entrar nesse sistema para matar nossa cultura, nossa dança, nosso canto, o respeito que temos pelas pessoas. Para onde nosso povo vai caminhar? Aonde nós queremos chegar? ${ }^{13}$

Encerro este artigo na certeza de que a temática não se encerra aqui, mas sim exigirá dos próprios índios (e também de nós, pesquisadores, assessores, aliados nesse processo de construção e garantia de sistemas indígenas de educação escolar) ainda muita reflexão e esforços.

\section{Notas}

1. O estudo foi realizado tendo como eixo referencial de análise os encontros anuais realizados pelo movimento dos professores indígenas do Amazonas, de Roraima e do Acre. Já foram realizados dez encontros (1988 a 1997), como poderá ser verificado no Quadro-síntese (Cf. anexo).

2. Entendo educação como todo conhecimento que uma comunidade ou povo possui e que é de domínio de todos, transmitido de pai para filho e necessário para viver bem. Nesse sentido, educação não é o mesmo que escola. É o processo por meio do qual toda pessoa aprende a viver. Essa aprendizagem se dá na família, na comunidade e no povo. Assim, o conceito de educação está intimamente ligado ao de cultura, como aprendizado social de determinadas estruturas, mecanismos e modelos exemplares, no contexto de cada sociedade. Há, então, uma grande confluência dos dois conceitos: cultura e ação pedagógica. Nesse processo, a educação escolar, ao surgir e se desenvolver como um novo espaço e tempo educativo, necessariamente deve basear-se nos princípios educativos e métodos próprios de aprendizagem dos povos indígenas, conforme garante, inclusive, a Constituição do Brasil, para então acrescentar outros conhecimentos, necessários para a vida atual.

3. Depoimento de Bruno, kaingang, durante sua participação na mesa-redonda intitulada: A posição das organizações indígenas, no encontro interno "Leitura e escrita em escolas indígenas: Domesticação x autonomia", durante o $10^{\circ}$ Cole, Unicamp, julho/95.

4. Depoimento do professor Orlando, macuxi, na mesa-redonda: A posição das organizações indígenas, no encontro interno "Leitura e escrita em escolas indígenas: Domesticação x autonomia", representando a Copiar, durante o $10^{\circ}$ Cole, Unicamp, julho/95.

5. Sobre essa temática, há, no segundo capítulo da tese, um item referente à relação entre povos indígenas e o Estado nacional - políticas e legislação indigenista no Brasil.

6. O termo "problemática indígena" refere-se aqui às questões históricas e atuais advindas do contato dos povos indígenas com a sociedade que os cerca. 
7. "A educação do índio será orientada para a integração na comunhão nacional mediante processo de gradativa compreensão dos problemas gerais e valores da sociedade nacional, bem como do aproveitamento de suas aptidões individuais."

8. Lamentavelmente, o projeto de lei do novo estatuto, que leva o título de "Estatuto das Sociedades Indígenas" e que deverá adequar-se à nova perspectiva constitucional, cujos princípios são o respeito à diversidade cultural e à autonomia dos povos indígenas - superando os antigos objetivos integracionistas -, encontra-se retido no Congresso Nacional, por orientação do próprio governo.

9. Há na tese, compondo o capítulo 2, um subitem que procura traçar um breve histórico da educação escolar indígena no Brasil e incorpora uma proposta de periodização elaborada por Mariana Leal em sua dissertação de mestrado intitulada "Da origem dos homens à conquista da escrita: Um estudo sobre povos indígenas e educação escolar no Brasil", que procura identificar diferentes fases e suas características principais.

10. O movimento articula hoje uma rede de 1.156 professores indígenas que trabalham com um universo de 25.902 alunos. Organiza-se em nove regiões: alto e médio Solimões; baixo Amazonas; alto, médio e baixo Madeira; rio Negro (no Amazonas); Roraima e Acre. Já participaram diretamente dos encontros anuais 390 professores de 32 povos.

11. Concordo com esse entendimento de que todos têm direito a uma educação de qualidade. Porém, como se sabe, o próprio conceito de qualidade não é único, e vem carregado dos interesses hegemônicos de dada sociedade. Com respeito à nossa, está intrinsecamente ligado à noção de desenvolvimento ("progresso"). Seria o caso de perguntar: que modelo de desenvolvimento? Que qualidade? A serviço e a favor de quem? Por outro lado, há que se considerar que faz parte do processo histórico e atual, vivido pela grande maioria dos povos indígenas, a percepção da apropriação do saber escolar como um valor. Em outras palavras, o desejo de concretizar o ideal da escolarização integra hoje as aspirações de grande parte dos povos indígenas (principalmente os de maior tempo de contato). É o que os índios do rio Negro têm chamado de "febre da escola", que faz com que comunidades quase inteiras se desloquem de suas áreas para os municípios mais próximos, a fim de dar continuidade aos estudos.

12. "A esperança é um condimento indispensável à experiência histórica. Sem ela, não haveria história, mas puro determinismo. Só há história onde há tempo problematizado e não pré-dado" (Freire 1997).

13. Depoimento do professor Euclides Pereira, do povo macuxi, durante o VIII Encontro dos Professores Indígenas do AM, RR e AC/1995. Euclides já foi coordenador do Conselho Indígena de Roraima (CIR) e da Organização dos Professores Indígenas de Roraima (Opir). Foi o primeiro representante indígena da região norte a participar do Comitê de Educação Escolar Indígena do MEC (tendo sido escolhido e indicado pelo movimento dos professores indígenas do AM, de RR e do AC). Atualmente, é coordenador-geral da Coordenação das Organizações Indígenas da Amazônia Brasileira (Coiab). 
Quadro dos Encontros

\begin{tabular}{|c|c|c|c|c|c|c|c|c|c|}
\hline ENCONTRO & ANO & LOCAL & $\begin{array}{l}\text { NÚM. } \\
\text { PAR- } \\
\text { TIC. }\end{array}$ & REGIŌES / ESTADO & $\begin{array}{l}\text { POV. } \\
\text { PARTIC. }\end{array}$ & PRINCIPAIS PONTOS & DOCUMENTOS PRODUZIDOS & ASSESSORIA & ORG. \\
\hline 1 & 1988 & $\begin{array}{l}\text { MANAUS } \\
\text { AM }\end{array}$ & 41 & $\begin{array}{l}\text { Alto rio Negro, alto e médio } \\
\text { Solimöes, baixo Amazonas-AM } \\
\text { e Roraima }\end{array}$ & 14 & $\begin{array}{l}\text { Formas originais de educação } \\
\text { Educaçăo escolar } \\
\text { Tipos de escola } \\
\text { Troca de experiências }\end{array}$ & $\begin{array}{l}\text { Documento final com os } \\
\text { posicionamentos resultantes } \\
\text { do Encontro de como a escola } \\
\text { deve ser }\end{array}$ & $\begin{array}{l}\text { CIMI } \\
\text { UNIV AMAZONAS }\end{array}$ & CIMI \\
\hline ॥ & 1989 & $\begin{array}{l}\text { MANAUS } \\
\text { AM }\end{array}$ & 30 & $\begin{array}{l}\text { Alto rio Negro, alto e médio } \\
\text { Solimões, baixo Amazonas-AM } \\
\text { e Roraima }\end{array}$ & 12 & $\begin{array}{l}\text { Continuidade da troca de experiências } \\
\text { O que cada grupo está fazendo para } \\
\text { conseguir a } \\
\text { escola que deseja } \\
\text { As dificuldades desse processo }\end{array}$ & $\begin{array}{l}\text { Documentos com reivindicaçōes } \\
\text { para a nova LDB encaminhado } \\
\text { ao Congresso Nacional }\end{array}$ & $\begin{array}{l}\text { CIMI } \\
\text { MARI-USP } \\
\text { UNICAMP }\end{array}$ & CIMI \\
\hline III & 1990 & $\begin{array}{l}\text { MANAUS } \\
\text { AM }\end{array}$ & 45 & $\begin{array}{l}\text { Alto rio Negro, alto e médio } \\
\text { Solimões, baixo Amazonas-AM } \\
\text { e Roraima }\end{array}$ & 13 & $\begin{array}{l}\text { Discussão específica sobre elaboração de } \\
\text { currículos diferenciados para as escolas } \\
\text { indígenas }\end{array}$ & & \begin{tabular}{|l} 
CIMI \\
MARI-USP \\
UNICAMP \\
UNIVAMAZONAS \\
\end{tabular} & COPIAR \\
\hline IV & 1991 & $\begin{array}{l}\text { MANAUS } \\
\text { AM }\end{array}$ & 43 & $\begin{array}{l}\text { Alto rio Negro, alto e médio } \\
\text { Solimōes, baixo Amazonas-AM } \\
\text { e Roraima }\end{array}$ & 17 & $\begin{array}{l}\text { Continuidade da discussăo sobre currículos } \\
\text { Estudo da legislação } \\
\text { Tema gerador } \\
\text { Articulação do movimento de professores com } \\
\text { o movimento indígena mais amplo }\end{array}$ & Declaração de Princípios & $\begin{array}{l}\text { CIMI } \\
\text { MARI-USP } \\
\text { UNICAMP } \\
\text { UNIVAMAZONAS }\end{array}$ & COPIAR \\
\hline $\mathrm{v}$ & 1992 & $\begin{array}{l}\text { BOA VISTA } \\
\text { RR }\end{array}$ & 90 & $\begin{array}{l}\text { Alto rio Negro, alto e médio } \\
\text { Solimōes, baixo Amazonas, } \\
\text { Madeira-AM, Roraima e } \\
\text { Envira-Acre }\end{array}$ & 15 & $\begin{array}{l}\text { Curriculos e regimentos } \\
\text { Tema gerador e diversidade cultural } \\
\text { Legislação / política governamental } \\
\text { /Estatuto do Indio } \\
\text { Continuidade do Movimento } \\
\text { Mobilizacăa A to - "500 anos" }\end{array}$ & $\begin{array}{l}\text { Posiçăo quantonao novo Estatuto } \\
\text { do Indio } \\
\text { Indicaçöes para o Comitê } \\
\text { Assessor/MẼC }\end{array}$ & $\begin{array}{l}\text { CIMI } \\
\text { MARI-USP } \\
\text { UNICAMP }\end{array}$ & COPIAR \\
\hline vi & 1993 & $\begin{array}{l}\text { BOA VISTA } \\
\text { RR }\end{array}$ & 115 & $\begin{array}{l}\text { Alto rio Negro, alto e médio } \\
\text { Solime és, baixo Amazonas, } \\
\text { Madeira-AM, Roraima e } \\
\text { Envira-Acre }\end{array}$ & 17 & $\begin{array}{l}\text { Culturas diversificadas } \\
\text { Exposiçáa artes / danças } \\
\text { Currículos e regimentos } \\
\text { Comitê assessor - MEC } \\
\text { Continuidade/articulação Movimento } \\
\end{array}$ & $\begin{array}{l}\text { Contra a Reyjisão Constitucional } \\
\text { Indicaçöes para o Comitê } \\
\text { Assessor/JMEC } \\
\text { o }\end{array}$ & $\begin{array}{l}\text { CIMI } \\
\text { MARI-USP } \\
\text { UNICAMP }\end{array}$ & COPIAR \\
\hline VII & 1994 & $\begin{array}{l}\text { MANAUS } \\
\text { AM }\end{array}$ & 76 & $\begin{array}{l}\text { Alto rio Negro, alto e médio } \\
\text { Solimöes, baixo Amazonas, } \\
\text { Madeira-AM, Roraima e Acre }\end{array}$ & 21 & $\begin{array}{l}\text { Medicina tradicional } \\
\text { Curriculos e regimentos } \\
\text { Política educacional }\end{array}$ & $\begin{array}{l}\text { Apoio Regimento Guarani } \\
\text { Indicaçãone critérios } \\
\text { participação } \backslash \text { Com itê } \\
\text { Nova Declaração }\end{array}$ & $\begin{array}{l}\text { CIMI } \\
\text { MARI-USP } \\
\text { UNICAMP }\end{array}$ & COPIAR \\
\hline VIII & 1995 & $\begin{array}{l}\text { BOA VISTA } \\
\text { RR }\end{array}$ & 130 & $\begin{array}{l}\text { Alto rio Negro, alto e médio } \\
\text { Solimöes, baixo Amazonas: } \\
\text { Mura e Munduruku, Madeira: } \\
\text { Sateré e Parintimtim-AM, } \\
\text { Roraima e Acre }\end{array}$ & 25 & $\begin{array}{l}\text { Lançamento do cartaz - Declaração } \\
\text { Situação atual das escolas } \\
\text { Escolas e projetos de futuro } \\
\text { Movimento dos professores e organizaçōes } \\
\text { indígenas } \\
\text { Continuidade/articulação Movimento }\end{array}$ & $\begin{array}{l}\text { Documento ao MEC (Comitế) } \\
\text { solicitando condiçốes para o } \\
\text { representante }\end{array}$ & $\begin{array}{l}\text { CIMI } \\
\text { MARI-USP } \\
\text { UNICAMP } \\
\text { OPAN }\end{array}$ & COPIAR \\
\hline $\mathrm{IX}$ & 1996 & $\begin{array}{l}\text { S. GBL. } \\
\text { CACHO- } \\
\text { EIRA } \\
\text { AM }\end{array}$ & 100 & $\begin{array}{l}\text { Alto rio Negro, alto e } \\
\text { médio Solimóes, alto, médio } \\
\text { e baixo Madeira, baixo } \\
\text { Amazonas, Roraima e Acre }\end{array}$ & 23 & $\begin{array}{l}\text { Escolas indigenas e projetos de futuro } \\
\text { Alternativas econôm icas e escola }\end{array}$ & $\begin{array}{l}a \\
\text { Doçumento final } \\
r\end{array}$ & $\begin{array}{l}\text { CIMI } \\
\text { MARI-USP } \\
\text { UNICAMP } \\
\text { OPAN } \\
\text { UNIV.AMAZONAS } \\
\end{array}$ & COPIAR \\
\hline $\mathrm{x}$ & 1997 & $\begin{array}{l}\text { MANAUS } \\
\text { AM }\end{array}$ & 105 & $\begin{array}{l}\text { Alto rio Negro, } \\
\text { alto e médio Solimões, } \\
\text { alto, médio e baixo Madeira, } \\
\text { baixo Amazonas, } \\
\text { Roraima e Acre }\end{array}$ & 32 & $\begin{array}{l}\text { Avaliação dos } 10 \text { anos de Movimento } \\
\text { Perspectivas de continuidade }\end{array}$ & $\begin{array}{l}\text { Documento ao MEC sobre RCI } \\
\text { Documento ao MEC sobre } \\
\text { Comitê } \\
\text { Documento-repúdio ao livro } A \\
F a\end{array}$ & $\begin{array}{l}\text { CIMI } \\
\text { MARI-USP } \\
\text { OPAN }\end{array}$ & COPIAR \\
\hline
\end{tabular}


The autonomy as value and the articulation of possibilities : the indigenous movement from Amazon, Roraima and Acre and the construction of an indigenous school education policy

\begin{abstract}
The present article tries to verify the cultural-politicalpedagogical role of the indigenous teachers movement from Amazon, Roraima and Acre in the construction of an indigenous school policy. The work itself is about the conception of "indigenous school" as a new form of education institution, defining it for the service of each indigenous people as an instrument of affirmation and cultural reelaboration. A school that can contribute to the conquest of a political place - in the field of education - by indigenous people, in the Brazilian State, searching for new intercultural relations, in the mark of the Brazilian recognition as a country of cultural plurality, even though the overcoming of an integrating perspective, counterparting, this way, to the reality idea of "schools for indigenous people". Yet the limits have been analyzed and the possibilities of the indigenous schools, as a political-cultural resource of affirmation of the identities in the confrontation with current reality, or in its confrontation referring to the inter-ethnic contact.
\end{abstract}

Bibliografia

BARTH, Frederik. Los grupos étnicos y sus fronteiras. La organización social de la diferencias culturales. México: Fondo de Cultura Económica, 1976.

BATALLA, Guillermo B. "La teoria del control cultural en estudio de procesos étnicos". Arinsana nํㅜ 10. Caracas, 1989.

CAPACLA, Marta Valéria. O debate sobre a educação indígena no Brasil (1975-1995). Brasília; São Paulo: MEC/Mari-USP, 1995.

CASTRO, Eduardo Viveiros de. "Autodeterminação indígena como valor". Anuário Antropológico/81. Fortaleza; Rio de Janeiro: Edições Universidade Federal do Ceará e Tempo Brasileiro, 1983.

CORRY, Stephen. "Prólogo". Guardianes de la tierra sagrada. Londres: Survival International, 1994.

CUNHA, Manuela Carneiro da. "O futuro da questão indígena". In: SILVA, A.L. e GRUPIONI, L.D. A temática indígena na escola: Novos subsídios para professores de $1^{\circ}$ e $2^{\circ}$ graus. Brasília: MEC/Mari/Unesco, 1995. 
D'ANGELIS, Wilmar e VEIGA, Juracilda (orgs.). Leitura e escrita em escolas indígenas. Campinas: ALB/Mercado de Letras, 1997.

FERREIRA, Mariana K. Leal. "Da origem dos homens à conquista da escrita: Um estudo sobre povos indígenas e educação escolar no Brasil”. Dissertação de mestrado, Departamento de Antropologia, USP, 1992.

FREIRE, Paulo. Pedagogia da autonomia. $3^{\mathrm{a}}$ ed. São Paulo: Paz e Terra, 1997.

GOHN, Maria da Glória. Movimentos sociais, cidadania e educação. São Paulo: Cortez, 1992.

MELIÀ, Bartomeu. Educação indígena e alfabetização. São Paulo: Loyola, 1979.

"El modelo Arakuarenda, o el bilingüismo radical". Elogio de la lengua guarani. Assunção: Cepag, 1995.

MOSONYI, Esteban Emilio. "Familia indígena y educación intercultural bilingüe". Comunicação apresentada no II Congreso Latinoamericano de Educación Intercultural Bilingüe. Santa Cruz, Bolívia, nov. 1996.

OLIVEIRA, Roberto Cardoso de. A crise do indigenismo. Campinas: Ed. da Unicamp, 1988.

PRICE, David. Informativo Funai $\mathrm{n}^{\circ}$ 14. Set. 1975.

SANTOS, Sílvio Coelho dos. Educação e sociedades tribais. Porto Alegre: Movimento, 1975.

SILVA, Aracy Lopes da. "Prefácio". In: CAPACLA, Marta Valéria. O debate sobre a educação indígena no Brasil (1975-1995). Brasília; São Paulo: MEC/Mari-USP, 1995.

SILVA, Aracy Lopes da e GRUPIONI, Luís Donisete. A temática indígena na escola: Novos subsídios para professores de $1^{\circ}$ e $2^{\circ}$ graus. Brasília: MEC/Mari/Unesco, 1995.

SILVA, Márcio. "A conquista da escola: Educação escolar e movimento de professores indígenas no Brasil". Em Aberto 63. Brasília, 1994. 